\title{
Censura ao teatro nos anos cinquenta Política, censores, organização e procedimentos
}

\author{
Ana Cabrera
}

No Estado Novo, a censura ao teatro não foi exercida sempre da mesma forma, nem obedeceu sempre aos mesmos diplomas legais, nem se subordinou aos mesmos quadros organizativos, regulamentos e quadro organizativo. As alterações que são patentes na actuação dos censores ao teatro durante o salazarismo são particularmente significativas se as observarmos a partir da problemática do que foram os anos cinquenta em Portugal.

Ao longo dos anos cinquenta a actuação das Comissões de Censura ao teatro varia, não como hesitação, mas sobretudo por efeito das divergências entre as forças políticas que apoiavam Salazar.

A relação entre as peças submetidas à Comissão de Censura, que eram todas as que se representavam em Portugal, e as que são proibidas constituem um bom indicador desta realidade:

\begin{tabular}{|c|c|c|c|}
\hline Ano & Peças submetidas à censura & Peças proibidas & $\%$ \\
\hline 1950 & 59 & 5 & 8,4 \\
1951 & 166 & 16 & 9,6 \\
1952 & 83 & 5 & 6 \\
1953 & 229 & 11 & 4,8 \\
1954 & 171 & 10 & 5,8 \\
1955 & 148 & 25 & 16,8 \\
1956 & 168 & 5 & 2,9 \\
1957 & 192 & 4 & 2 \\
1958 & 215 & 16 & 7,4 \\
1959 & 193 & 8 & 4,1 \\
\hline
\end{tabular}

As mudanças nas pastas ministeriais e as consequentes mexidas no aparelho censório são factores que explicam estas oscilações. Assim, a década de cinquenta é marcada pela influência de três Ministros da Presidência e três Secretários Nacionais do SNI (Secretariado Nacional de Informação). Podemos, então, estabelecer uma periodização que se baseia essencialmente na identificação de diferentes políticas para as Comissões de Censura. Estas diferentes políticas assentam essencialmente no olhar dos Ministros da Presidência sobre a missão da censura em função do seu papel estratégico no Estado Novo.

De facto, a clivagem inicia-se em 1953. Antes, estamos perante uma política para o SNI que é ainda herdeira da forte personalidade de António Ferro. Entre 1950 e 1953, o Secretário Nacional do SNI foi António Eça de Queiroz, que mais não faz do que manter o quadro político de censores e aplicar as medidas estatuídas.

Pelo contrário, o ano de 1953 foi de grandes mudanças na estrutura e organização da censura aos espectáculos. É nesta altura que entra em vigor um novo regime jurídico (Decreto-Lei 38964 de 27 de Outubro de 1952), se adopta a designação de Comissão de Censura aos Espectáculos e se define a sua composição que se consubstanciava na intervenção da Presidência do Conselho, do Ministério da Justiça e do Ministério da Educação Nacional na nomeação dos censores. Paralelamente, constitui-se a Comissão de Literatura e Espectáculos para Menores a trabalhar conjuntamente com a Comissão de Censura. Para além destas alterações de pendor organizacional, esta Comissão passa a aplicar o sistema de classificação dos espectáculos por idades.

Uma outra mudança muito significativa foi a renovação completa do quadro dos vogais da Comissão e a nomeação de um novo Secretário Nacional do SNI, José Manuel da Costa.

Este periodo (1953-56) da censura aos espectáculos caracteriza-se por um compromisso entre a redefinição das políticas censórias e o prosseguimento do controlo político, veiculação de uma moral, religião e estética oficial.

As questões que os censores colocam neste periodo situam-se sobretudo nas dúvidas a propósito da aplicação

\section{Ana Cabrera}

é doutorada em História Institucional e Política Contemporânea e investigadora do Centro de Investigação Media e Jornalismo da Universidade Nova de Lisboa. Desenvolve vários projectos que relacionam os media e a política. 
do novo quadro legal, as medidas e atitudes concretas a tomar e o enquadramento da política governamental a que se tinham que ajustar. A classificação dos espectáculos por idades tinha efeitos directos no público. Muitos jornais, mesmo os afectos ao regime, criticaram a medida o que provocou uma reacção por parte do Presidente da Comissão que sublinhou "a maior repulsa pelos baixos propósitos do ataque contra uma medida de flagrante oportunidade e necessidade tomada pelo Governo que outra coisa não teve em vista do que a sanidade moral do País, a salvaguarda da formação espiritual das futuras gerações e a defesa das idades perigosas contra a acção nociva de muitos espectáculos que antes Ihes eram facultados" (Acta de 24 de Fevereiro de 1953).

Neste periodo, definiram-se também critérios acerca da actuação da Comissão de Censura face à obra de Gil Vicente. Trata-se de uma questão colocada pelo Presidente a de saber se "se devem ou não efectuar cortes nas peças de Gil Vicente". Embora a Comissão tenha optado por não cortar o teatro vicentino, não deixa de ser interessante citar a opinião de dois censores que discordaram da decisão: Cortês Pinto e Garcia Domingues. Estes foram de opinião que "só em sessões de estudo ou de fins culturais se poderia permitir a representação integral das referidas peças, porque, em espectáculos públicos, há apenas a considerar o efeito que a representação produz no público em geral (...) tanto mais que, num público indiferenciado, é natural que a maior parte das pessoas não tenha qualquer ideia sobre o teatro de Gil Vicente" (Acta de 20 de Abril de 1954).

Em 1956 entramos nitidamente numa outra fase da actuação da censura. O Ministro da Presidência é Marcello Caetano e escolhe para Secretário Nacional do SNI Eduardo Brazão. Também ao nivel dos quadros dos censores houve alterações com a nomeação de dois novos vogais. Desde logo, e mesmo antes da publicação de novos despachos, verifica-se uma revisão dos critérios da censura. A este propósito, Eduardo Brazão participou à Comissão que reconhecia a necessidade de proceder a uma revisão das peças de teatro proibidas pela censura, não só porque grande número delas são da autoria dos nossos melhores escritores teatrais, mas ainda pelos benéficos efeitos que essa medida traduz na obra de ressurgimento do teatro em Portugal, solicitando da inspecção dos espectáculos a lista completa das peças naquelas condições. Examinada a referida lista, havia resolvido, com a concordância de sua Excelência o Ministro, levantar desde já a suspensão da representação das peças reprovadas pelas Comissões anteriores, não o fazendo para as reprovadas pela actual Comissão, por atenção para com os seus membros, a quem contudo solicita a revisão das suas decisões, tendo presente as novas directivas para a censura teatral e que se resumem no seu seguinte despacho:

Dado o facto de que os espectáculos teatrais são hoje classificados para os menores, há que rever as peças que no passado foram proibidas. De futuro assenta-se nestas normas para a proibição:

Imoralidade sem outro objectivo do que a explorar. Propaganda velada ou aberta da doutrina comunista. (17 de Abril de 1956)

Na sequência da aprovação destas novas regras, a peça $A$ conspiradora foi aprovada por maioria sem classificação especial (Acta de 24 de Abril de 1956). Na reunião de Maio, foi levantada a proibição a outras trinta peças de autores portugueses. Também foi decidido aplicar "às peças de autores estrangeiros de reconhecido valor a doutrina do despacho de 17 de Abril" (Acta de 19 de Junho de 1956). Simultaneamente, em relação aos ensaios gerais decidiram aplicar critérios mais rigorosos:

Desejo que os senhores censores sejam exigentes e firmes quando assistam aos ensaios gerais das peças de teatro. Em primeiro lugar é indispensável que todos os artistas estejam vestidos e caracterizados como para as representações em público.

Em segundo lugar, no caso de se não terem cumprido quaisquer dos cortes deverão pedir novo ensaio.

(Eduardo Brazão, 25 de Setembro de 1956)

Não obstante esta política de maleabilidade da iniciativa de Marcello Caetano, continuaram os cortes nas revistas e nas peças de teatro. Mas não restam dúvidas de que o número de peças proibidas desceu substancialmente para o indicador de 2,9\% em $1956 \mathrm{e}$ 
2\% em 1957. A política de abertura e de uma certa suavização dos critérios censórios que caracterizaram a direcção política de Marcello Caetano, em relação aos serviços da censura, chega ao fim com a sua saída do Ministério da Presidência. A partir de Setembro de 1957, inicia-se uma outra fase caracterizada pelo regresso a uma grande dureza de critérios. Pedro Teotónio Pereira é o novo Ministro da Presidência.

Curiosamente, a nova lei só virá a ser publicada em 1959. Até essa altura, a alteração das práticas e dos critérios foram orientadas a partir das indicações que os censores recebiam do novo Secretário Nacional do SNI, Eurico Simões Serra, antigo censor, com bastantes anos de experiência na Comissão de Censura, que apresenta à Comissão as suas ideias: "a missão em que estamos investidos é uma missão de confiança que implica uma especial fidelidade a directrizes e instruções que superiormente nos forem dadas. (...) A Comissão tem de manter a constante preocupação de definir e orientar critérios por forma à regularidade e uniformidade das suas decisões. Só assim conseguirá dignificar-se e prestigiar-se" (Acta de 25 de Fevereiro de 1958).

Os censores começam a apresentar queixas acerca de abusos que se cometiam depois do ensaio para a Comissão: alteração de cenas, adereços e textos. Estas ocorrências eram mais comuns no teatro de revista e menos recorrentes no teatro declamado. Por esta altura, verifica-se que a acção sobre o teatro se radicaliza: aumenta o número de peças proibidas, aumentam os cortes e sobretudo agravase a acção e intervenção dos censores sobre as peças em cena. A Comissão orienta-se então para uma supervisão sistemática aos espectáculos, tanto por parte dos censores, como por parte da Inspecção aos Espectáculos.

A sua acção ficou marcada pela proibição de quadros nas revistas e pela aplicação de multas aos artistas e às companhias. As actas das reuniões da Comissão enchemse de participações das comunicações dos censores. 0 próprio Presidente da Comissão realiza deslocações aos teatros e revela que, tendo assistido à revista Pernas à vela, verificou que as determinações da censura não foram respeitadas nomeadamente em relação à "dança do ventre" de forma que "o referido número resulta obsceno". 0 mesmo se aplicava ao número do "florista", em que o actor Humberto Madeira contracena com Eugénio Salvador, "pela forma como aquele artista interpreta a figura de um homossexual, se apresenta inconveniente e imoral": "A comissão resolveu por unanimidade suprimir o primeiro daqueles números e propôs à inspecção dos espectáculos a aplicação de uma multa ao actor Humberto Madeira pelas modificações introduzidas ao número do florista" (Acta de 18 de Março de 1958).

A revista Fogo no pandeiro foi particularmente visada pelos censores em diversas reuniões. Os censores Alambre dos Santos, Cortes Pinto e Alves Pereira informam que no número do horóscopo daquela revista, a artista continua a não ocultar a "região umbilical". Este número viria mesmo a ser proibido a partir de 9 de Maio (Acta de 6 de Maio de 1958).

0 rigor dos censores recrudesce em relação aos aspectos de natureza moral e de natureza política, tanto mais que a candidatura de Humberto Delgado à Presidência da República estava a provocar um "terramoto político". 0 censor Simão Gonçalves apresenta queixa do actor Emílio Correia que, na revista Abaixo as saias, citou palavras, fora do texto, dirigidas ao General Humberto Delgado, o que redundou num inquérito sumário e confidencial sobre o assunto" (Acta de 1 de Julho de 1958).

Pedro Teotónio Pereira manter-se-á na pasta de Ministro da Presidência até 1961 mas, mesmo após a sua saida, esta política será assegurada, reforçada e justificada em função dos problemas políticos que o regime vai enfrentar - a guerra colonial.

\section{Referências bibliográficas}

\section{Fundo do SNI.}

Processos da Direcção Geral dos Serviços dos Espectáculos.

Actas das reuniões da Comissão de Exame e Classificação de Espectáculo 1950-1970.

Decreto-Lei 38964, de 27 de Outubro de 1952.

Circular n. ${ }^{\circ}$ 589, de 25 de Fevereiro de 1950.

Decreto-Lei n. 42663, de 1959. 